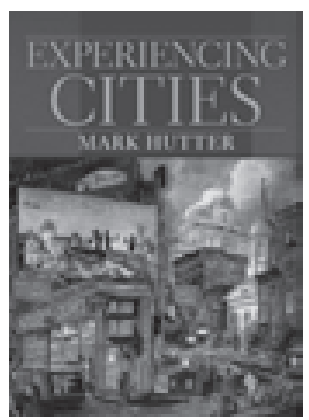

\title{
Mark Hutter. Experiencing cities
}

\author{
Boston: Pearson, 2007, 496 p.
}

Henrique Dorneles de Castro ${ }^{1}$

El carácter urbano de la sociedad sirve como justificación para la existencia de la sociología urbana, que tiene como objetivo de estudio a la ciudad, centro de la civilización y el lugar en el cual la cultura se desarrolla (y es desarrollada). Con ello se inicia el libro de Mark Hutter, donde se expone la gran cantidad de habitantes en las metrópolis, realizando una descripción histórica de la evolución de la población urbana en el mundo, así como la localización de los mayores aglomerados antiguos y actuales.

En el segundo capítulo, Hutter se remonta a los orígenes de los asentamientos urbanos, explicando que la revolución agrícola crea las condiciones necesarias para la primera revolución urbana y el surgimiento de la urbe: stock de comida e instituciones para controlar su distribución. Luego realiza un paralelo entre este modelo y la teoría de los intercambios de Jane Jacobs, según quien estas prácticas corresponden al elemento clave para la creación de las ciudades, y no la agricultura.

El tercer capítulo se interna en el mundo urbano reciente: la revolución industrial (segunda revolución urbana) y el surgimiento de la sociología urbana. Aquí se enfatizan los cambios ocurridos con la revolución, debido a su grandiosidad. El autor trae consideraciones sobre las primeras ciudades europeas modernas, tomando a Manchester

1 Estudiante de pregrado, Departamento de Geografía, Universidade Federal de Rio Grande do Sul. Email: henrique.dorneles@ufrgs.br como "La ciudad"2 del siglo XVIII. En una discusión epistemológica, Hutter recuerda los tipos desarrollados por sociólogos del y para el periodo, como lo son el cambio de comunidad (tradiciones) a sociedad (contratos) vistos en Maine y Tonnies.

En el cuarto capítulo relata los dos principales paradigmas de la escuela de Chicago: ecología urbana y urbanismo. El autor intenta realizar una búsqueda conceptual y también sobre la evolución del pensamiento sociológico, tomando a Chicago como la ciudad de la época, caracterizándose esta corriente por la visión de ciudad como un sistema con modelos cerrados y patrones claros de comportamiento. El modelo de urbe de Burgess, en que la ciudad se desarrollaría en círculos concéntricos perfectos, tal vez sea el mejor ejemplo a la crítica. La escuela de Chicago es vista como una distorsión brutal de la naturaleza de los seres humanos, sin espacio para la psicología social.

El quinto capítulo trata la temática de la planificación urbana, dejando para el siguiente capítulo la discusión sobre política económica urbana. En este apartado son expuestos los modelos urbanos, sus cualidades, defectos y críticas. Destaca a Burnham y el movimiento por el embellecimiento de la ciudad; la ciudad jardín de Ebenezer Howard (que se expone como modelo, sin éxito luego de la crisis económica de 1929); la ciudad expandida de Wright, privatizada

\footnotetext{
2 Ciudad que sintetiza las característica urbanas que marcan una determinada época.
} 
y arborizada y los rascacielos de Le Corbusier. También presenta ejemplos de poder de intervención y de la capacidad que posee el estado sobre las ciudades de New York, Portland y Filadelfia. Finalmente Hutter se dedica a exponer los planteamientos de Jane Jacobs, contrarias a la tendencia imperante de expansión en los suburbios y al abandono de la esfera pública.

El sexto capítulo expone las ideas de la escuela de Los Ángeles que, con los cambios de gobierno y económicos de la época de los 30 y de posguerra, debió reformular sus conceptos en cuanto a sociología urbana. Los principios de la escuela de Chicago sobre fuerzas naturales y de libre mercado que estructuraban los patrones urbanos perdieron sentido frente a las intervenciones gubernamentales, además del hecho ya citado que fue ignorar el componente cultural. David Harvey utiliza entonces una visión marxista de política económica para evaluar los conflictos sociales, trayendo consigo las ideas de que el espacio no es solamente un fenómeno físico, siendo las personas aquellas que le entregan una interpretación cultural.

Hutter también expone las ideas de Soja, Davis y Dear, con el fin de caracterizar la ciudad actual posmoderna; el autor utiliza el modelo de Dear para contrastar el modelado de las zonas concéntricas: elementos colocados en forma lineal y en grilla, en una adecuación bastante compleja determinada por el Capitalismo ${ }^{3}$. A continuación se discuten variados elementos de la sociología, como la máquina de crecimiento urbano, la perspectiva socioespacial, la discusión de Zukin acerca de a quién pertenece la ciudad y la cultura, la imagen urbana y el significado simbólico del lugar, las políticas de poder y la memoria colectiva.

La tercera parte del libro trata sobre las imágenes de la ciudad, en el séptimo capítulo, con ejemplos de ellas y resignificaciones ocurridas. En este sentido, considera Pa-

\footnotetext{
3 Procesos de decisión y actos que influencian los patrones de uso de suelo de las ciudades posmodernas.
}

rís como la ciudad luz para los impresionistas, que debió pasar por una reforma urbana burguesa-Haussmanization, y New York y la escuela de Ashcan, con una visión opuesta, que muestra el submundo como el realismo social en las artes. El autor habla sobre los murales callejeros, que sirven como vía de expresión de una territorialidad o entonces como una forma de toma del poder del gobierno, cuando organiza los programas de artes de murales y ya no es más la comunidad quien se encarga de ello. El octavo capítulo trata específicamente sobre un símbolo, los rascacielos. Estos tendrían como significado el poder que las corporaciones poseen, siendo la imagen física imponente de todo el poder. Hutter finaliza el capítulo recurriendo al ataque contra World Trade Center, explicando su poder simbólico, precisamente por haber sido dirigido al mayor ícono del capitalismo financiero.

La cuarta parte trata sobre la psicología social, las relaciones entre las personas en la ciudad. En ella, el noveno capítulo analiza el orden público, exponiendo sobre tres esferas de la sociedad: lo privado, parroquial y público. El espacio público es tratado bajo el punto de vista de Lofland, que considera seis usos del mismo, entre los que se encuentra el ser el lugar de la práctica política y del contacto con lo diferente, generando tolerancia. Con esto trae también la idea de Oldenburg sobre los terceros lugares como sitios para el encuentro, conversación, paseos, entretenimiento, lugares informales de reunión. La vitalidad de una vida en comunidad dependerá entonces de la existencia y calidad de esos terceros lugares. El ámbito público generará contacto con el sujeto diferente, extraño, y con la multitud, tornando en muchas ocasiones al sujeto en un anónimo. Hutter discute respecto a la situación de los extranjeros en el espacio público; las personas concurren a estos espacios porque en ellos se sienten bien y seguros. Esta seguridad se entrega por la presencia de otros, y en el momento que el espacio público se torna vacío, se vuelve inseguro y pasa a ser evitado. En el transcurso de todo el capítulo el autor muestra la importancia del ámbito público y se muestra contrario a la privatización del mismo, pues lo considera un elemento esencial y fundador de la ciudad moderna. 
El capítulo décimo abarca el desorden de la ciudad y la ecología del miedo. Hutter concuerda con Sennet, quien propone que la vida social contemporánea está sufriendo a consecuencia del colapso de la vida pública y la falta de sociabilidad de las personas. De acuerdo con Jacobs, dicha sociabilidad era aprendida desde el contacto con lo diferente, con los extraños familiares del espacio público, hechos que ocurren cada vez menos en la medida en que se privatiza más la sociedad. Hutter también trata aspectos relacionados con la exclusión de los afrodescendientes en la esfera pública, sobre la teoría de la ventana quebrada ${ }^{4}$ y la ecología del miedo y su consecuente fortificación de la vigilancia urbana.

En el capítulo undécimo analiza los enclaves étnicos y guetos, las políticas sociales que los originan y los mantienen. Compara los guetos negros con los enclaves de inmigrantes blancos y diferencia la hipersegregación (negros) de la asimilación (inmigrantes blancos) en la ciudad; además, incorpora en el estudio los proyectos de renovación urbana que fueron conocidos como remoción de negros y la gentrificación (transformación de barrios pobres en ricos a través de migración de población). En tanto, en el capítulo duodécimo se realiza una discusión acerca de las distinciones entre géneros dadas al interior de la ciudad, diferencias de trato y acoso; el rol de los derechos de los homosexuales en la ciudad, de las tribus urbanas y de las clases creativas; los cambios en los lugares de trabajo de acuerdo con la localización de la fuerza del mismo.

El último capítulo sobre la población de las ciudades se refiere a las relaciones de parentesco. En él, Hutter muestra el cambio que la revolución industrial causó en las relaciones entre parientes, en que a partir del siglo XVII el concepto de familia como unidad nuclear pasó a existir. Antes de la revolución industrial, las actividades eran públicas y el aislamiento no existía, pues no era posible debido a la densidad de población.

\footnotetext{
4 Broken windows (tradución libre): teoría para la cual pequeños delitos tolerados llevan a delitos mayores y a una atmósfera del miedo.
}

La familia era solo una parte de la sociedad integrada como un todo. Desde la revolución industrial la vida comenzó a privatizarse, surgiendo la familia nuclear y aumentando la importancia de las relaciones de parentesco.

En la sexta parte de la obra, el autor indaga en el significado de los lugares urbanos, abordando el shopping center y los complejos deportivos de béisbol, desde la importancia que poseen para la ciudad. Dentro de ello enfatiza la trascendencia de las grandes casas comerciales en los grandes centros comerciales periféricos que no poseen identificación con el lugar en que se encuentran. En cuanto al béisbol, el autor utiliza el deporte como un ejemplo del cambio de lo rural a lo urbano: en este caso dicho deporte, que habría comenzado en el interior, alcanzó proyección en los centros urbanos. A través del deporte y de los medios de comunicación se crea y fomenta el sentimiento de orguIlo nacionalista.

El capítulo decimoséptimo dedicado a la suburbanización de los Estados Unidos de América, se inicia con una discusión de los conceptos de suburbio, definido en términos espaciales y simbólicos; se discute también temas como la relación entre las razas (etnias) y los suburbios, dado el carácter eminentemente racista de estos. En relación con los aspectos estructurales, toma consideraciones en cuanto a los condominios cerrados (fortificación de los suburbios), el nuevo urbanismo (que intenta adoptar otro modelo urbano) y la localización de los jardines en las viviendas: situados al fondo para evitar el contacto y esconderse de lo público.

Luego el autor discute sobre el capital social y su disminución frente a una mayor privatización de la sociedad, enfocado en la tecnología, que permite el aislamiento del lugar y la conectividad global. Hutter demuestra problemas públicos que pueden ser provocados por el aislamiento social, como por ejemplo, la ola de muertes de adultos mayores en Europa -que vivían en la soledad- que terminaban siendo prisioneros de sus propias viviendas, debido a que la esfera pública era cada vez más disminuida. 
El último capítulo abarca distintas ciudades en el mundo, ampliando la visión; inicia la discusión con las características del desarrollo de los países del tercer mundo, debido a que el espacio es el reflejo de la producción. Expone las teorías sobre los modelos de desarrollo, como el de la modernización, la desarrollista y de la dependencia, concordando con Castells en cuanto a que no hay un modo en que los países subdesarrollados surjan al modelo de los desarrollados (debido a que el desarrollo fue alcanzado por medio de la explotación de los subdesarrollados). Hutter termina exponiendo las contradicciones inherentes al sistema y sus consecuencias sociales expresadas en los conflictos urbanos.

\section{Consideraciones finales}

Experiencing cities es un libro que sirve como introducción a la sociología urbana, pero que es aplicable a innumerables ciencias. Pese a centrarse en los Estados Unidos de América, Hutter consigue realizar observaciones globales y pertinentes; incluso los capítulos específicos son de gran utilidad debido al carácter homogéneo de los procesos del capital. El libro se vuelve una lectura básica para cualquier discusión sobre el tema urbano, siendo un material introductorio pero a la vez profundo, de gran aporte a discusiones sobre la cuestión urbana, altamente recomendado para cualquier estudioso del tema.

El libro entrega conceptos y teorías que pueden y deben ser aplicados en el análisis de lo urbano, como los procesos de revitalización urbana -y sus ideologías-. Las ideas en defensa del espacio público, inclusive en una sociedad privatizada en sí misma, demuestra la importancia de este espacio como esencial para la sociedad, para la seguridad y para la gobernabilidad. 